\title{
Dolutegravir Sodium
}

National Cancer Institute

\section{Source}

National Cancer Institute. Dolutegravir Sodium. NCI Thesaurus. Code C148408.

The sodium salt form of dolutegravir, an orally bioavailable integrase strand-transfer inhibitor (INSTI), with activity against human immunodeficiency virus type 1 (HIV-1) infection. Upon oral administration, doluteg ravir binds to the active site of integrase, an HIV enzyme that catalyzes the transfer of viral genetic material into human chromosomes. This prevents integrase from binding to retroviral deoxyribonucleic acid (DNA), and blocks the strand transfer step, which is essential for the HIV replication cycle. This prevents HIV-1 replication. 